\title{
Crescimento de Mudas de Eucalyptus grandis e Eremanthus erythropappus sob Diferentes Formulações de Substrato
}

\author{
Lucas Amaral de Meloํㅜ, Gabriel de Assis Pereira², \\ Edson Júnio Costa Moreira ${ }^{2}$, Antonio Claudio Davide ${ }^{2}$, \\ Eduardo Vinícius da Silva ${ }^{1}$, Luís Antônio Fonseca Teixeira ${ }^{2}$ \\ ${ }^{1}$ Departamento de Silvicultura, Universidade Federal Rural do Rio de Janeiro - UFRRJ, Seropédica/RJ, Brasil \\ ${ }^{2}$ Departamento de Ciências Florestais, Universidade Federal de Lavras - UFLA, Lavras/MG, Brasil
}

\section{RESUMO}

O objetivo deste trabalho foi avaliar a sobrevivência e o crescimento de mudas de Eucalyptus grandis e Eremanthus erythropappus, além de analisar o custo do substrato produzido, em função de diferentes formulações utilizadas. Dessa forma, para cada espécie, foi utilizado um experimento instalado em delineamento inteiramente casualizado (DIC), com as dez formulações de substrato contendo esterco de curral curtido, casca de arroz carbonizada, fibra de coco - estes variando nas proporções de 0, 30, 60 e 90\% - e vermiculita média (10\%). Ao final do processo de produção, foram quantificados: o percentual de sobrevivência, a altura da parte aérea e o diâmetro do coleto das mudas. Além disso, foi calculado o custo para produzir um metro cúbico de cada um dos dez substratos analisados. Verificou-se que os substratos influenciam significativamente o crescimento de ambas as espécies, sendo que o esterco influenciou de forma negativa no crescimento das mudas de candeia, enquanto, para o eucalipto, influenciou positivamente. O aumento de proporções de esterco diminuiu o custo por metro cúbico de substrato.

Palavras-chave: eucalipto, candeia, esterco bovino, fibra de coco.

\section{Growth of Eucalyptus grandis and Eremanthus erythropappus Seedlings under Different Substrate Formulas}

\begin{abstract}
The aim of this study was to evaluate the survival and growth of Eucalyptus grandis and Eremanthus erythropappus seedlings, besides analyzing the cost of the substrate produced according to the different formulas used. To this end, for each species, a completely randomized experimental design was carried out with ten substrate formulas containing cattle manure, carbonized rice husk, coconut fiber (at the proportions of 0, 30, 60 and 90\%), and vermiculite $(10 \%)$. At the end of the production process, the following variables were quantified: survival percentage, shoot height, and stem diameter of seedlings. Moreover, the cost to produce one $\mathrm{m}^{3}$ of each of the ten substrates analyzed was calculated. It was verified that the substrates significantly influenced the growth of both species: cattle manure negatively affected the growth of candeia seedlings and positively influenced the growth of eucalyptus seedlings. Increasing proportions of cattle manure reduced the cost per $\mathrm{m}^{3}$ of substrate.
\end{abstract}

Keywords: eucalyptus, candeia, cattle manure, coconut fiber. 


\section{INTRODUÇÃO}

O gênero Eucalyptus engloba o grupo de espécies florestais mais plantadas e pesquisadas no Brasil (Araújo, 2010; SFB, 2010) e no mundo (Pryor, 1976; FAO, 1981). A eucaliptocultura é a base da silvicultura nacional e, na maioria dos casos, é utilizada como modelo para o desenvolvimento da silvicultura de outras espécies menos conhecidas. Um exemplo do exposto está relacionado ao processo de produção de mudas em viveiro.

Neste contexto, nos últimos anos, Eremanthus erythropappus (DC.) MacLeish., uma espécie florestal nativa, tem sido alvo de uma série de pesquisas, devido à sua importância econômica e ambiental (Pérez et al., 2004; Silva et al., 2005; Estopa et al., 2006; Tonetti et al., 2006; Melo et al., 2012). O interesse pela espécie é em razão da sua madeira bruta, que apresenta alta resistência e durabilidade (Melo et al., 2012), mas, principalmente, da extração de seu óleo, que contém o alfabisabolol (Scolforo et al., 2002).

Além do interesse comercial, Eremanthus erythropappus forma maciços florestais nativos que, segundo Oliveira-Filho \& Fluminhan Filho (1999), funcionam como um tampão antifogo para outras formações florestais, em função da sua resistência a regimes moderados de incêndios. No entanto, resultados relacionados aos fatores que interferem na produção de mudas desta espécie ainda são escassos (Chaves \& Ramalho, 1996; Venturin et al., 2005; Silva et al., 2007; Scolforo et al., 2008; Davide \& Melo, 2012).

Dentre os fatores que interferem na sobrevivência, no crescimento e no padrão de qualidade de mudas de espécies florestais, destacam-se os componentes do substrato e suas respectivas proporções (Carneiro, 1995). Segundo Davide \& Silva (2008), os substratos utilizados pelos viveiristas na produção de mudas em tubetes têm apresentado as mais variadas composições, tendo como característica a não utilização de solo. Diversamente, para a produção de mudas em sacos plásticos, o principal componente da mistura é o solo (Carneiro, 1995; Davide \& Silva, 2008; Gomes \& Paiva, 2011).

Como principais componentes utilizados na formulação do substrato para tubetes, podem-se citar: compostos orgânicos, moinha de carvão, casca de arroz carbonizada, vermiculita, serragem e substratos comerciais, dentre inúmeros outros componentes que, puros ou misturados, são utilizados nos viveiros florestais (Davide \& Silva, 2008). Contudo, a composição do substrato irá depender de inúmeros fatores. Artur et al. (2007) citam a disponibilidade do material como sendo um dos principais. Outros fatores são: as espécies a serem produzidas; a qualidade e o custo de cada componente, e a proximidade com o viveiro, pois o custo do frete é relativamente alto.

Em grande parte dos viveiros de produção de mudas de essências florestais, é utilizado o esterco bovino como fonte orgânica (Andrade Neto et al., 1999). Sua principal característica não está no fato de ser um fornecedor de nutrientes às plantas, mas sim por contribuir para melhorar as condições físicas, químicas e biológicas do solo (Jorge, 1983), aumentando a capacidade de troca catiônica e de retenção de água (Primavesi, 1982).

Outro constituinte bastante utilizado é a casca de arroz carbonizada. Klein et al. (2002) observaram que este material pode ser utilizado para melhorar as propriedades físico-hídricas de substratos, propiciando melhor porosidade.

Pode ser citada ainda a vermiculita, considerada um substrato praticamente inerte, sendo necessário o maior fornecimento de nutrientes por meio de adubações periódicas (Gomes \& Paiva, 2011). Para os mesmos autores, se utilizada em grandes proporções, não é um bom material para a agregação do sistema radicular. Porém, é um componente que ajuda na porosidade e na retenção de água pelo substrato (Moniz, 1972).

Mais recentemente, outros materiais têm sido incorporados ao processo, como é o caso da fibra de coco (Davide \& Silva, 2008), um componente que até há pouco tempo era relatado como grande problema ambiental para as empresas que têm este material como resíduo do processo de produção (Freitas et al., 2010). Lacerda et al. (2006) comentam que a estrutura da fibra de coco, associada às suas propriedades físico-químicas, torna-a particularmente adequada para ser utilizada como substrato.

Diante disso, a adoção do sistema de produção e a escolha do substrato influenciam na quantidade e na qualidade das mudas, nos custos de produção 
e no lucro do viveiro. Assim, é importante realizar, além da análise técnica, a análise econômica, a fim de produzir mudas de qualidade com o menor custo possível (Dias et al., 2011).

Com base na importância da escolha dos constituintes do substrato de produção de mudas e suas respectivas proporções, este trabalho teve como objetivo avaliar a sobrevivência e o crescimento de mudas de Eucalyptus grandis e Eremanthus erythropappus, além de analisar o custo por metro cúbico de substrato produzido, em função de diferentes formulações de substrato à base de esterco de curral, casca de arroz carbonizada, fibra de coco e vermiculita.

\section{MATERIAL E MÉTODOS}

O experimento foi conduzido em delineamento inteiramente casualizado, independente para cada espécie, na área experimental do Viveiro Florestal da Universidade Federal de Lavras, em Lavras, Minas Gerais, no ano de 2010.

Em ambos os experimentos, foram utilizadas dez formulações de substrato contendo esterco de curral curtido, casca de arroz carbonizada, fibra de coco (esses variando nas proporções de 0, 30, 60 e 90\%) e vermiculita média (10\%) (Tabela 1).

Tabela 1. Formulação dos substratos utilizados na produção de mudas de Eucalyptus grandis e Eremanthus erythropappus.

Table 1. Substrates formulation used in the production of seedlings of Eucalyptus grandis and Eremanthus erythropappus.

\begin{tabular}{|ccccc|}
\hline \multirow{2}{*}{ Tratamentos } & \multicolumn{4}{c|}{ Constituintes $(\%-\mathbf{V} / \mathbf{V})$} \\
\cline { 2 - 5 } & A & B & C & D \\
\hline 1 & 00 & 00 & 90 & 10 \\
\hline 3 & 00 & 30 & 60 & 10 \\
\hline 4 & 00 & 60 & 30 & 10 \\
\hline 5 & 00 & 90 & 00 & 10 \\
\hline 6 & 30 & 00 & 60 & 10 \\
\hline 7 & 30 & 30 & 30 & 10 \\
\hline 8 & 30 & 60 & 00 & 10 \\
\hline 9 & 60 & 00 & 30 & 10 \\
\hline 10 & 60 & 30 & 00 & 10 \\
\hline
\end{tabular}

A: esterco de curral; B: casca de arroz carbonizada; C: fibra de coco; D: vermiculita.
Todos os tratamentos receberam adubos de liberação lenta (19:06:10 NPK) - $5 \mathrm{~kg}$ de adubo por metro cúbico de substrato. Para a produção de mudas de eucalipto, foi utilizado adubo com liberação entre 3 e 4 meses, e para a produção de mudas de candeia, adubo com liberação entre 5 e 6 meses, tendo como base o período de tempo necessário para formação das mudas de ambas as espécies.

Utilizaram-se tubetes de plástico rígido como recipientes para a produção das mudas, os quais foram dispostos em bandejas plásticas planas, encanteiradas a um metro acima do nível do solo, sobre uma estrutura metálica, a pleno sol. Para o eucalipto, foram utilizados tubetes com capacidade de $55 \mathrm{~cm}^{3}$ e, para a candeia, tubetes de $105 \mathrm{~cm}^{3}$.

No caso do eucalipto, foram semeadas, aproximadamente, cinco sementes por tubete, num total de 32 tubetes por parcela. Para a candeia, também foram semeadas, aproximadamente, cinco sementes por tubete, porém num total de 108 tubetes por parcela. Após esta operação, para ambas as espécies, as sementes foram cobertas com o mesmo substrato utilizado no enchimento dos recipientes e, sobre as bandejas, foi colocada tela sombrite 50\%, como forma de proteção contra a ação de gotas de chuvas e radiação direta. Assim que observado o fim da emergência, a tela foi retirada. Aos 30 e 45 dias após a semeadura, respectivamente, para o eucalipto e a candeia, foi realizado o raleio, deixando-se apenas uma plântula por recipiente. Aos 110 e 145 dias, foram avaliadas a sobrevivência, a altura da parte aérea $(\mathrm{cm})$ e o diâmetro do coleto $(\mathrm{mm})$ de um total de 12 e 20 mudas por parcela, para o eucalipto e para a candeia, respectivamente.

No início do processo de produção das mudas de candeia, verificou-se a ocorrência de doença fúngica, causando tombamento das mudas. Com o aparecimento da doença e a identificação do fungo causador (Rhizoctonia sp.), foi feito o tratamento com aplicação de Monceren 250 SC, um fungicida protetor e específico para o controle de rizoctoniose (Brasil, 2013), na dosagem de $3 \mathrm{ml} \mathrm{L}^{-1}$, aplicando a solução sobre as mudas, por meio de regador.

Os dados obtidos foram analisados segundo metodologia proposta por Banzatto \& Kronka (1992). A análise de variância (ANOVA) e os testes 
de médias foram feitos com auxílio do Programa Estatístico SisVar (Ferreira, 2011).

Por fim, para a avaliação do custo da produção por metro cúbico de cada um dos dez substratos utilizados, foram considerados os valores de compra dos constituintes utilizados na formulação. Estes valores foram obtidos para a região de Lavras e atualizados para o ano de 2012 (Tabela 2).

Pelo fato de o esterco bovino e a casca de arroz necessitarem de pré-tratamento antes de sua utilização como substrato, foram acrescidos aos valores monetários de compra os valores relacionados a perdas nos volumes originais adquiridos. $\mathrm{O}$ esterco bovino necessitou ser processado por uma peneira de meia polegada antes de sua utilização e a casca de arroz foi carbonizada. Estas perdas foram quantificadas durante o processo de produção dos substratos, no próprio Viveiro.

O custo de produção dos substratos formulados foi calculado de acordo com o custo de cada material e sua proporção para a formulação, por metro cúbico de substrato. $\mathrm{O}$ valor da adubação de base foi o mesmo para todos os tratamentos $\left(\mathrm{R} \$ 115,00 / \mathrm{m}^{3} \mathrm{de}\right.$ substrato), não sendo computado no valor final de cada um dos dez substratos formulados.

\section{RESULTADOS E DISCUSSÃO}

As dez formulações do substrato para as mudas de eucalipto não causaram diferença significativa quanto à sobrevivência, sendo que, em todos os tratamentos, o percentual de mortalidade foi inferior a 5\% (Figura 1a). No entanto, quando analisada a sobrevivência das mudas de candeia, pôde-se verificar que os tratamentos com maiores percentuais de esterco apresentaram altas taxas de mortalidade das mudas (Figuras la e 1b). Devido à alta mortalidade, não foi possível analisar os valores de altura e de diâmetro do coleto das mudas de candeia nos tratamentos com esterco bovino nas proporções de 60 (tratamentos 8 e 9) e 90\% (tratamento 10).

Ao avaliar os fatores que interferem no crescimento das mudas, a análise inicial deve ser realizada a fim de verificar se estes causam redução da sobrevivência das plantas. A sobrevivência é de suma importância, uma vez que, mesmo apresentando menor crescimento, a muda ainda pode ser recuperada por meio de técnicas utilizadas pelo viveirista.

Dentre as principais técnicas que o viveirista pode lançar mão para auxiliá-lo no processo de produção, podem-se citar - conforme elucidado por Carneiro (1995), Andrade Neto et al. (1999), Davide \& Silva (2008), Alfenas et al. (2009), Gomes \& Paiva (2011) e Davide \& Melo (2012) - as adubações de cobertura, a alternagem, o sombreamento, o manejo das irrigações e o controle de pragas e doenças, dentre outras.

Conforme pode ser observado, é inviável produzir mudas de candeia com a utilização de altas proporções de esterco bovino. Isolando o fator esterco, é possível verificar nitidamente a influência negativa da utilização de maiores proporções deste constituinte na sobrevivência (Figura 1b) e, consequentemente, na produção das mudas de candeia.

Um dos fatores que influenciaram na maior mortalidade de mudas de candeia, na medida em que se aumentavam as proporções de esterco no substrato, foi a incidência de um fungo do gênero Rhizoctonia (Figura 2), conforme relatado por Davide \& Melo (2012). Verificou-se, durante a condução do experimento, que as sementes de candeia apresentaram elevada taxa de emergência em todos os substratos testados, porém, por volta de

Tabela 2. Valor de compra dos componentes do substrato utilizados no viveiro para a região de Lavras, MG, no ano de 2012.

Table 2. The buy value of the substrate components used in the nursery for Lavras, MG, in 2012.

\begin{tabular}{cccc}
\hline Componente & Unidade & Valor de compra & Valor por m $^{\mathbf{3}}$ \\
\hline Esterco de curral bruto & Caminhão com $6 \mathrm{~m}^{3}$ & $\mathrm{R} \$ 300,00$ & $\mathrm{R} \$ 50,00$ \\
Casca de arroz in natura & Caminhão com $6 \mathrm{~m}^{3}$ & $\mathrm{R} \$ 350,00$ & $\mathrm{R} \$ 58,33$ \\
\hline Vermiculita (granulometria média) & Sacos de 100 litros & $\mathrm{R} \$ 31,00$ & $\mathrm{R} \$ 310,00$ \\
\hline Fibra de coco & Sacos de 100 litros & $\mathrm{R} \$ 24,30$ & $\mathrm{R} \$ 243,00$ \\
\hline
\end{tabular}


(a)
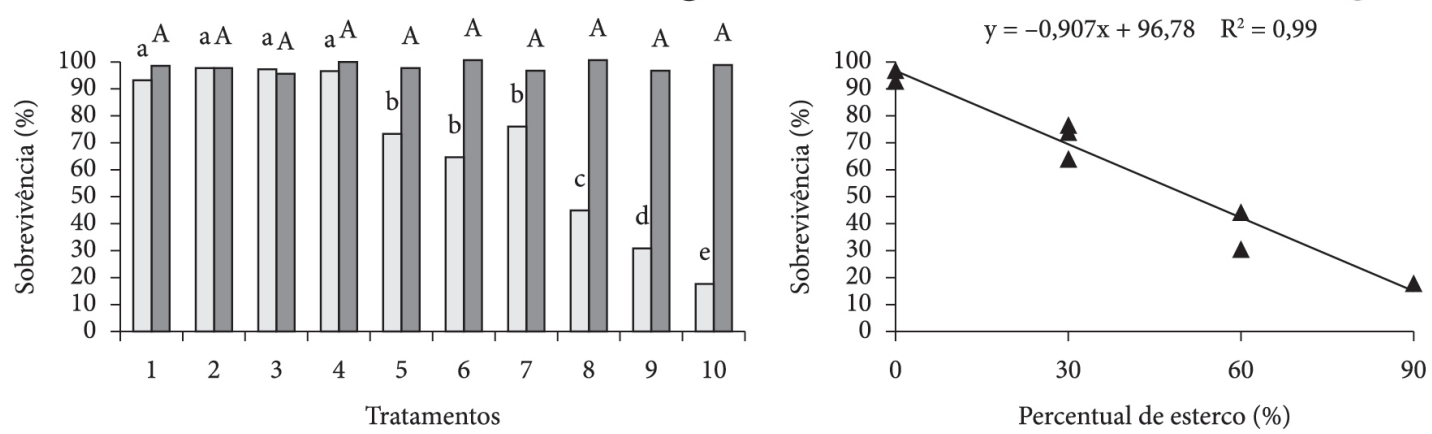

$\square$ Candeia $\square$ Eucalipto

Figura 1. a) Sobrevivência média de mudas de candeia e de eucalipto, aos 145 e 110 dias após a semeadura, respectivamente, em função das diferentes formulações de substrato; b) Sobrevivência de mudas de candeia aos 145 dias após a semeadura, em função do percentual de esterco presente no substrato.

Figure 1. a) Median survival of seedlings of candeia e eucalipto, at 145 and 110 days after sowing, respectively, due to the substrates different; b) Seedling survival of candeia at 145 days after sowing, depending on the percentage of cattle manure in the substrate. Médias seguidas da mesma letra, dentro da mesma espécie, não diferem estatisticamente pelo teste de Scott-Knott a 5\% de probabilidade.
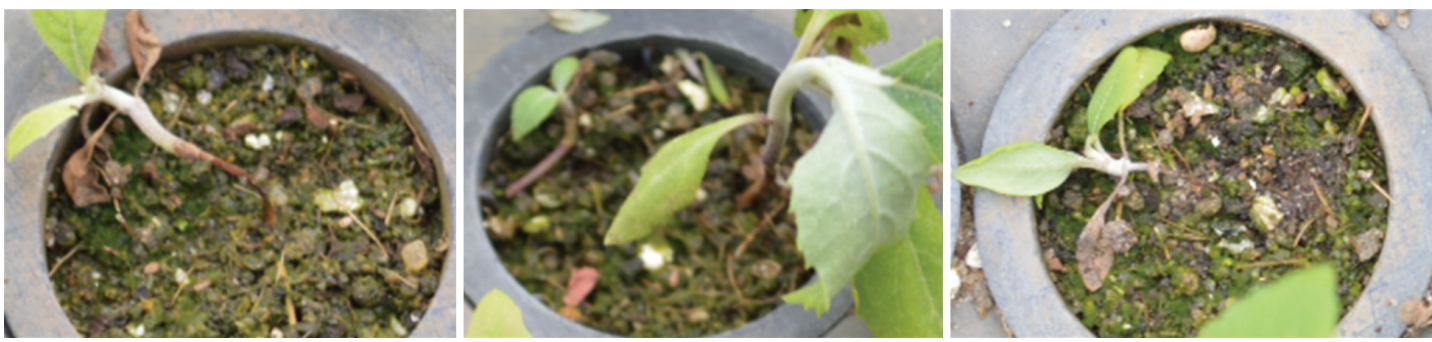

Figura 2. Tombamento de mudas jovens de Eremanthus erythropappus, causado por fungo do gênero Rhizoctonia. Figure 2. Damping off of Eremanthus erythropappus seedlings caused by Rhizoctonia.

25 dias após a semeadura, as mudas começaram a apresentar sintomas de damping off.

Conforme verificado neste trabalho, o damping offé mais ocorrente nas mudas de candeia produzidas em substratos com maior proporção de esterco. O sintoma desta doença nas mudas desta espécie fica evidente por uma lesão deprimida na região do coleto (Figura 2), seguida pelo tombamento e posterior morte das mudas, conforme observado por Davide \& Melo (2012). Esses sintomas levam à interrupção do fluxo de seiva, causada pelo anelamento do floema (Alfenas et al., 2009). Desta forma, recomenda-se evitar o uso de esterco para a formulação de substratos na produção de mudas de E. erythropappus.

Com relação ao crescimento das mudas, ao se analisarem os valores médios da altura da parte aérea e do diâmetro do coleto, referentes às mudas de candeia (Tabela 3), verificou-se que, assim como ocorreu para a sobrevivência, estas características foram influenciadas negativamente pela presença de esterco. Portanto, além da maior mortalidade de mudas causada pela sua presença, o esterco causou redução no crescimento das mudas, conforme se pode verificar ao comparar os tratamentos sem esterco no substrato (tratamentos 1, 2, 3 e 4) aos tratamentos com $30 \%$ deste componente (tratamentos 5, 6 e 7).

O menor crescimento das mudas de candeia, quando foi utilizado esterco no substrato, pode estar relacionado às características físicas que este componente orgânico confere ao substrato de produção. De acordo com dados de Guerrini \& Trigueiro (2004), substratos formados à base de compostos orgânicos apresentam predominância 
Tabela 3. Valores médios para as características altura da parte aérea (Alt) e diâmetro do coleto (DC) de mudas de candeia e eucalipto, aos 145 e 110 dias após a semeadura, respectivamente, em função do substrato utilizado.

Table 3. Mean values for height and stem diameter characteristics of eucalipto and candeia seedlings, at 145 and 110 days after sowing, respectively, depending on the substrate used.

\begin{tabular}{|c|c|c|c|c|c|}
\hline \multirow{2}{*}{ Tratamentos } & \multirow{2}{*}{$\begin{array}{c}\text { Constituintes }(\%-V / V) \\
\text { A/B } / C / D^{*}\end{array}$} & \multicolumn{2}{|c|}{ Candeia } & \multicolumn{2}{|c|}{ Eucalipto } \\
\hline & & Alt (cm) & $\mathrm{DC}(\mathrm{mm})$ & Alt (cm) & $\mathrm{DC}(\mathrm{mm})$ \\
\hline 1 & $00 / 00 / 90 / 10$ & $20,06 \mathrm{a}$ & $3,61 \mathrm{a}$ & $14,27 \mathrm{~b}$ & $2,14 \mathrm{c}$ \\
\hline 2 & $00 / 30 / 60 / 10$ & $21,15 \mathrm{a}$ & $3,78 \mathrm{a}$ & $13,45 \mathrm{~b}$ & $2,12 \mathrm{c}$ \\
\hline 3 & $00 / 60 / 30 / 10$ & $16,77 \mathrm{~b}$ & $3,33 \mathrm{~b}$ & $13,64 \mathrm{~b}$ & $2,27 \mathrm{c}$ \\
\hline 4 & $00 / 90 / 00 / 10$ & $13,24 \mathrm{c}$ & $3,01 \mathrm{~b}$ & $13,22 \mathrm{~b}$ & $2,28 \mathrm{c}$ \\
\hline 5 & $30 / 00 / 60 / 10$ & $5,19 \mathrm{~d}$ & $1,64 \mathrm{~d}$ & $15,74 \mathrm{~b}$ & $2,57 \mathrm{~b}$ \\
\hline 6 & $30 / 30 / 30 / 10$ & $7,28 \mathrm{~d}$ & $1,96 \mathrm{c}$ & $14,58 \mathrm{~b}$ & $2,58 \mathrm{~b}$ \\
\hline 7 & $30 / 60 / 00 / 10$ & $7,30 \mathrm{~d}$ & $2,28 \mathrm{c}$ & $14,40 \mathrm{~b}$ & $2,66 \mathrm{~b}$ \\
\hline 8 & $60 / 00 / 30 / 10$ & - & - & $20,01 \mathrm{a}$ & $3,08 \mathrm{a}$ \\
\hline 9 & $60 / 30 / 00 / 10$ & - & - & $20,62 \mathrm{a}$ & $3,06 \mathrm{a}$ \\
\hline 10 & $90 / 00 / 00 / 10$ & - & - & 17,99 a & $3,21 \mathrm{a}$ \\
\hline
\end{tabular}

${ }^{*}$ A: esterco de curral; B: casca de arroz carbonizada; C: fibra de coco; D: vermiculita. Médias seguidas da mesma letra na coluna não diferem estatisticamente pelo teste de Scott-Knott a 5\% de probabilidade.

de microporos em detrimento dos macroporos. Consequentemente, acumula-se mais água, o que, atrelado à espécie utilizada, pode gerar problemas durante o processo de produção. Isso, de certa forma, pode ser comprovado pela maior incidência de fungos e pela mortalidade em mudas de candeia, à medida que se aumentou a proporção de esterco. Deve-se enfatizar que a candeia é uma espécie que ocorre, naturalmente, em sítios com solos pouco férteis e com baixo teor de matéria orgânica (Pérez et al., 2004).

Além da questão física, pode-se inferir também sobre a influência das características químicas do esterco sobre a sobrevivência e o crescimento de mudas de candeia. No entanto, pouco se sabe a respeito da nutrição desta espécie, tanto em campo quanto no viveiro. De acordo com Venturin et al. (2005), em experimento com adubação mineral, a partir da técnica do elemento faltante, a ausência de $\mathrm{P}$ e $\mathrm{N}$ afeta drasticamente o crescimento de mudas de candeia, enquanto altos níveis de $\mathrm{Zn}$ no substrato podem reduzir o crescimento das plantas.

No caso da candeia, mesmo que os melhores resultados tenham ocorrido na ausência do esterco bovino, é possível verificar, dentre os quatro tratamentos sem este constituinte, o maior crescimento das mudas nos tratamentos 1 e 2 , os quais tinham a fibra de coco como constituinte em maior proporção. Estes foram os únicos tratamentos que apresentaram altura média das plantas acima de
$20 \mathrm{~cm}$, mostrando que este componente é uma boa alternativa para a formulação do substrato, conforme mencionado por Lacerda et al. (2006) e Davide \& Silva (2008)

Ressalta-se ainda que, para qualquer um dos componentes utilizados, deve-se ter atenção quanto à sua origem, o que pode afetar a qualidade do material. De acordo com Carrijo et al. (2002), as propriedades físico-químicas da fibra de coco, por exemplo, variam bastante em função da fonte de matéria-prima e do seu processamento, podendo apresentar níveis tóxicos de tanino, de cloreto de potássio e de sódio.

Ao observar as características de crescimento das mudas de eucalipto, nota-se que os menores valores foram obtidos na ausência de esterco e os maiores valores para altura e diâmetro de coleto das mudas foram encontrados nos substratos com 60 e $90 \%$ de esterco em sua composição (Tabela 3). Mesmo que a formulação do substrato não tenha influenciado nos percentuais de sobrevivência das mudas de eucalipto, é necessário avaliar o crescimento durante todo o processo, uma vez que o substrato interfere nas características de qualidade das mudas, tais como a altura da parte aérea e o diâmetro do coleto.

Com relação aos valores médios de altura da parte aérea das mudas de eucalipto, independentemente de os tratamentos 8, 9 (60\% de esterco) e 10 (90\% deste constituinte) não terem apresentado diferenças significativas, o tratamento com $90 \%$ de esterco 
apresentou média da altura das mudas inferior a $20 \mathrm{~cm}$, valor mínimo utilizado como referência de qualidade para mudas (Carneiro, 1995).

Analisando-se o custo do substrato, conforme salientado anteriormente, para a casca de arroz e o esterco de curral, perdas volumétricas ocorrem devido à necessidade de beneficiamento destes materiais. Com base nos resultados destas operações, a carbonização da casca de arroz apresentou um rendimento volumétrico de aproximadamente $60 \%$, enquanto o esterco de curral, depois de passado pela peneira de meia polegada, teve $85 \%$ de seu volume aproveitado para a preparação do substrato.

Desta forma, de acordo com a Tabela 4, verificase que, variando as proporções de três dos quatro constituintes utilizados, o custo por metro cúbico de substrato preparado é bastante alterado. Dentre os substratos testados, o que apresentou o custo mais elevado para ser produzido, o tratamento 1 , é cerca de $213 \%$ mais caro do que o substrato que leva $90 \%$ de esterco de curral (tratamento 10) em sua composição, que foi o mais barato $\left(\mathrm{R} \$ 77,95 / \mathrm{m}^{3}\right)$.

Com base no aproveitamento do substrato, notase mais uma vez, conforme elucidado para a fibra de coco, a importância da fonte de matéria-prima e do beneficiamento. No caso do esterco, principalmente em função de onde se obtém este componente, o aproveitamento pode ser modificado em função da granulometria com que o esterco chega ao viveiro.
Além disso, deve-se ressaltar a preferência por esterco adquirido em curral cimentado, reduzindo a quantidade de impurezas frequentes neste tipo de material (areia, argila, sementes de plantas daninhas etc.). Já, para a casca de arroz carbonizada, o que mais interfere em seu aproveitamento final é o processo de carbonização, que pode queimar parte da casca in natura em vez de carbonizá-la.

De acordo com Simões et al. (2012), além do custo do substrato em si, é de suma importância considerar a qualidade das mudas e o tempo necessário para a sua produção. Verificou-se que a produção de mudas de Eucalyptus grandis é mais fácil de ser conduzida em relação às mudas de candeia. Para o eucalipto, a mortalidade de mudas é a mesma, independentemente do substrato utilizado (Figura 1), além de esta espécie apresentar ciclo de produção mais curto em relação à candeia. Somado a isto, as mudas de eucalipto apresentaram maior crescimento nos substratos com maiores percentuais de esterco de curral, um componente que, para a maioria dos viveiros no Estado de Minas Gerais, é de fácil aquisição e barato, reduzindo os custos de produção.

Já para a candeia, à medida que se aumenta a proporção de esterco de curral no substrato, a sobrevivência e o crescimento das plantas reduzemse drasticamente. Desta forma, para que sejam produzidas mudas de qualidade desta espécie em tubetes, aconselha-se utilizar a fibra de coco como

Tabela 4. Custo por metro cúbico de cada constituinte pronto para ser utilizado e dos dez substratos formulados, com base em valores de compra para o ano de 2012, na região de Lavras-MG.

Table 4. Cost by $\mathrm{m}^{3}$ of each constituent ready to be used the ten substrates formulated based on the buy amounts for the year 2012, in Lavras, MG.

\begin{tabular}{|c|c|c|c|c|c|}
\hline \multirow{2}{*}{ Tratamentos } & \multicolumn{4}{|c|}{ Constituintes $(\%-\mathrm{V} / \mathrm{V})$} & \multirow{2}{*}{ Custo do substrato $/ \mathrm{m}^{3}$} \\
\hline & $\mathbf{A}$ & $\mathbf{B}$ & $\mathrm{C}$ & D & \\
\hline 1 & 00 & 00 & 90 & 10 & $\mathrm{R} \$ 243,70$ \\
\hline 2 & 00 & 30 & 60 & 10 & $\mathrm{R} \$ 195,80$ \\
\hline 3 & 00 & 60 & 30 & 10 & $\mathrm{R} \$ 147,90$ \\
\hline 4 & 00 & 90 & 00 & 10 & $\mathrm{R} \$ 100,00$ \\
\hline 5 & 30 & 00 & 60 & 10 & $\mathrm{R} \$ 188,45$ \\
\hline 6 & 30 & 30 & 30 & 10 & $\mathrm{R} \$ 140,55$ \\
\hline 7 & 30 & 60 & 00 & 10 & $\mathrm{R} \$ 92,65$ \\
\hline 8 & 60 & 00 & 30 & 10 & $\mathrm{R} \$ 133,19$ \\
\hline 9 & 60 & 30 & 00 & 10 & $\mathrm{R} \$ 85,29$ \\
\hline 10 & 90 & 00 & 00 & 10 & $\mathrm{R} \$ 77,95$ \\
\hline Custo do constituinte $/ \mathrm{m}^{3}$ & $\mathrm{R} \$ 58,82$ & $\mathrm{R} \$ 83,33$ & $\mathrm{R} \$ 243,00$ & $\mathrm{R} \$ 250,00$ & \\
\hline
\end{tabular}

A: esterco de curral; B: casca de arroz carbonizada; C: fibra de coco; D: vermiculita. 
constituinte em maior proporção, o que acaba elevando o custo de produção. Portanto, verifica-se que utilizar os resultados obtidos na produção de mudas de eucalipto para escolher o substrato a ser utilizado na produção de mudas de candeia não seria a melhor opção, uma vez que os resultados são contrastantes.

\section{CONCLUSÕES}

As mudas de eucalipto e candeia responderam de forma diferenciada à composição do substrato e às proporções dos seus constituintes. $\mathrm{O}$ esterco influenciou de forma negativa no crescimento das mudas de candeia, enquanto, para o eucalipto, influenciou positivamente. Além disso, o aumento de proporções de esterco diminuiu o custo por metro cúbico de substrato produzido.

\section{STATUS DA SUBMISSÃO}

Recebido: 10 jul., 2013

Aceito: 11 mar., 2014

Publicado: 30 jun., 2014

\section{AUTOR(ES) PARA CORRESPONDÊNCIA}

\section{Lucas Amaral de Melo}

Departamento de Silvicultura, Universidade Federal Rural do Rio de Janeiro - UFRRJ, CEP 23890-000, Seropédica, RJ, Brasil e-mail: lucas.amaral@ufv.br

\section{REFERÊNCIAS}

Alfenas AC, Zauza AAV, Mafia RG, Assis TF. Clonagem e doenças do eucalipto. 2. ed. Viçosa: UFV; 2009. 500 p.

Andrade Neto A, Mendes ANG, Guimarães PTG. Avaliação de substratos alternativos e tipo de adubação para a produção de mudas de cafeeiro em tubetes. Ciência e Agrotecnologia 1999; 23(2): 270-280.

Araújo MS. Manejo de espécies florestais para produção de madeira, forragem e restauração de áreas degradadas. Caicó: EMPARN; 2010. 60 p.

Artur AG, Cruz MCP, Ferreira ME, Barretto VCM, Yagi R. Esterco bovino e calagem para formação de mudas de guanandi. Pesquisa Agropecuária Brasileira 2007; 42(6): 843-850. http://dx.doi.org/10.1590/S0100204X2007000600011
Banzatto DA, Kronka SN. Experimentação Agrícola. 2. ed. Jaboticabal: FUNEP; 1992. 247 p.

Brasil. Ministério da Agricultura Pecuária e Abastecimento - MAPA. Monceren 250 SC. 2013. 10 p. [cited 2013 Mar 21]. Available from: http://www. agricultura.pr.gov.br/arquivos/File/defis/DFI/Bulas/ Fungicidas/MONCEREN_250_SC.pdf.

Carneiro JGA. Produção e controle de qualidade de mudas florestais. Curitiba: Campos/UENF; 1995. 451 p. PMCid:PMC502818.

Carrijo AO, Liz RS, Makishima N. Fibra da casca do coco verde como substrato agrícola. Horticultura Brasileira 2002; 20(4): 533-535. http://dx.doi.org/10.1590/S010205362002000400003

Chaves MMF, Ramalho RS. Estudos morfológicos em sementes, plântulas e mudas de duas espécies arbóreas pioneiras da família Asteraceae (Vanillosmopsis erythropappa Schult. Bip. e Vernonia discolor SprengKess.). Revista Árvore 1996; 20(1): 1-7.

Davide AC, Melo LA. Produção de mudas de candeia. In: Scolforo JR, Oliveira AD, Davide AC. O manejo sustentável da candeia: o caminhar de uma nova experiência florestal em Minas Gerais. Lavras: Editora UFLA; 2012. cap. 3, p. 43-60.

Davide AC, Silva EAA. Produção de sementes e mudas de espécies florestais. Lavras: UFLA; 2008. 174 p.

Dias BAS, Marques GM, Silva ML, Costa JMFN. Análise econômica de dois sistemas de produção de mudas de eucalipto. Revista Floresta e Ambiente 2011; 18(2): 171177. http://dx.doi.org/10.4322/floram.2011.035

Estopa RA, Souza AM, Moura MCO, Botrel MCG, Mendonça EG, Carvalho D. Diversidade genética em populações naturais de candeia (Eremanthus erythropappus (DC.) MacLeish). Scientia Forestalis 2006; (70): 97-106.

Food and Agriculture Organization of the United Nations - FAO. Eucalypts for planting: FAO forestry and forest products studies. Rome: FAO; 1981. $403 \mathrm{p}$.

Ferreira DF. Sisvar: a computer statistical analysis system. Ciência e Agrotecnologia 2011; 35(6): 10391042.

Freitas TAS, Barroso DG, Souza LS, Carneiro JGA, Paulino GM. Produção de mudas de eucalipto com substratos para sistema de blocos. Revista Árvore 2010; 34(5): 761-770. http://dx.doi.org/10.1590/S010067622010000500001

Gomes JM, Paiva HN. Viveiros Florestais: propagação sexuada. Viçosa: UFV; 2011. 116 p.

Guerrini IA, Trigueiro RM. Atributos físicos e químicos de substratos compostos por biossólidos e casca de arroz carbonizada. Revista Brasileira de Ciências do Solo 2004; 28(6): 1069-1076. http://dx.doi.org/10.1590/ S0100-06832004000600016 
Jorge JA. Manejo e adubação. Compêndio de Edafologia. 2. ed. São Paulo: Ed. Nobel; 1983. 309 p.

Klein VA, Camara RK, Simon MA, Dias ST. Casca de arroz carbonizada como condicionador de substrato. In: Furlani AMC. Caracterização, manejo e qualidade de substrato para produção de plantas. Campinas: Instituto Agronômico; 2002. 95 p. (Documentos IAC, n. 70).

Lacerda MRB, Passos MAA, Rodrigues JJV, Barreto LP. Características físicas e químicas de substratos à base de pó de coco e resíduo de sisal para produção de mudas de sabiá (Mimosa caesalpiniaefolia Benth). Revista Árvore 2006; 30(2): 163-170. http://dx.doi.org/10.1590/ S0100-67622006000200002

Melo LA, Davide AC, Teixeira LAF. Metodologia para resgate de matrizes e enraizamento de estacas de Eremanthus erythropappus. Cerne 2012; 18(4): 631-638. http://dx.doi.org/10.1590/S0104-77602012000400013

Moniz AC. Elementos de pedologia. São Paulo: Ed. da Universidade de São Paulo; 1972. 459 p.

Oliveira-Filho AT, Fluminhan Filho M. Ecologia da vegetação do parque florestal Quedas do Rio Bonito. Cerne 1999; 5(2): 51-64.

Pérez JFM, Scolforo JRS, Oliveira AD, Mello JM, Borges LFR, Camolesi JF. Sistema de manejo para a candeia - Eremanthus erythropappus (DC.) Macleish - a opção do sistema de corte seletivo. Cerne 2004; 10(2): 257-273.

Primavesi A. O manejo ecológico do solo. São Paulo: Ed. Nobel; 1982. 542 p. PMCid:PMC1039816.

Pryor LD. The biology of Eucalyptus. London: Edward Arnold; 1976. 82 p. PMCid:PMC1475213.

Scolforo JRS, Davide AD, Oliveira AD, Silva CPC, Acerbi Junior FW, Andrade IS et al. Manejo de plantações de candeia. Lavras: UFLA; 2008. 26 p.
Scolforo JRS, Oliveira AD, Davide AC. Manejo sustentável da candeia Eremanthus erythropappus e Eremanthus incanus: relatório técnico científico. Lavras: UFLA-FAEPE, 2002. 350 p.

Serviço Florestal Brasileiro - SFB. Florestas do Brasil em resumo - 2010: dados de 2005-2010. Brasília: SFB; 2010. $152 \mathrm{p}$.

Silva AC, Rosado SCS, Calegário N, Rodrigues EAC, Oliveira AN, Vieira CT. Variações genéticas na qualidade do sistema radicular de mudas de candeia (Eremanthus erythropappus (DC.) MacLeish). Revista Árvore 2007; 31(4): 609-617. http://dx.doi.org/10.1590/ S0100-67622007000400005

Silva AC, Rosado SCS, Vieira CT. Variação genética entre e dentro de procedências de candeia (Eremanthus erythropappus) para a resposta à inoculação com fungos micorrízicos arbusculares. Revista Brasileira de Engenharia Agrícola e Ambiental 2005; 9(3): 400-405. http://dx.doi.org/10.1590/S1415-43662005000300016

Simões D, Silva RBG, Silva MR. Composição do substrato sobre o desenvolvimento, qualidade e custo de produção de mudas de Eucalyptus grandis Hill ex Maiden × Eucalyptus urophylla S. T. Blake. Ciência Florestal 2012; 22(1): 91-100. http://dx.doi. org/10.5902/198050985082

Tonetti OAO, Davide AC, Silva EAA. Qualidade física e fisiológica de sementes de Eremanthus erythropappus (DC.) Macleish. Revista Brasileira de Sementes 2006; 28(1): 114-121. http://dx.doi.org/10.1590/S010131222006000100016

Venturin N, Souza PA, Macedo RLG, Nogueira FD. Adubação mineral da candeia (Eremanthus erythropappus (DC.) McLeish). Floresta 2005; 35(2): 211-219. 